\title{
A clinical study of dengue fever cases: NRI Medical College, Chinakakani, Andhra Pradesh, South India
}

\section{Kakarla Thota Kanugolu Murali Mohan, \\ Bunga Bhaskara Rao, Chikkala Raghuram, Shirisha Gunnam, Dhulipalla Dharmateja, Aparanji Gopidi}

Department of Medicine, NRI General Hospital and Academy of Sciences and Medical College, Chinakakani, Guntur, Andhra Pradesh, India

Address for the Correspondence: Dr. K.T.K. Murali Mohan, Department of Medicine, NRI General Hospital and Academy of Sciences and Medical College, Chinakakani, Guntur, Andhra Pradesh, India. E-mail: kanugolu15@gmail.com

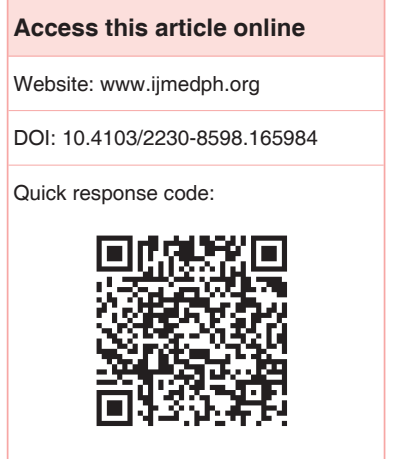

Background: Admission of dengue fever/dengue hemorrhagic fever cases was on the rise during the monsoon period of 2013 in NRI Hospital and surrounding Districts of Coastal Andhra Pradesh. A number of deaths due to dengue fever were reported in the previous months. Hence, a clinical study of the dengue cases was done in the late monsoon for a period of 3 months since a large number of cases with bleeding manifestations were referred to our Hospital for platelets transfusion from the local hospitals and nursing homes. Aim: A Clinical study of dengue fever cases in the extended monsoon period and to evaluate the need for platelet transfusion in dengue fever cases. Retrospective Observational Study - Results: In the retrospective observational study, the diagnostic serotyping was done using rapid standard diagnostic kits. Eighty-four dengue seropositive were seen of which dengue fever cases were 55, dengue hemorrhagic fever were 27 and dengue shock syndrome were 2 cases only. Totally, 26 cases with dengue hemorrhagic fever whose platelet counts were below 50,000 cells/cu $\mathrm{mm}$, were given random pooled donor platelet concentrates, while two cases of dengue shock syndrome were given single donor platelet concentrates, fresh frozen plasma and whole blood transfusion. Timely platelets transfusions in cases of dengue hemorrhagic fever and dengue shock syndrome helped to prevent severe hemorrhagic complications, and there were no deaths.

Key words: Clinical study, dengue hemorrhagic fever, monsoon period, platelet transfusions

\section{AIMS AND OBJECTIVES OF THE STUDY}

The monsoon period usually lasts from June to September every year in the Indian Peninsula. However, during the year 2013, the monsoon extended until mid-November due to a number of cyclones in the Bay of Bengal. As NRI Medical College caters to the needs of the coastal districts of Guntur Krishna, Prakasham and Nellore of Andhra Pradesh and Nalgonda of Telangana, vector borne diseases such as malaria, Chikungunya and dengue fever cases were on the rise. As per the reports of National Vector Borne Diseases Survey 1996-2006, Andhra Pradesh reported the incidence of 2\% of dengue fever cases. Of 197 cases of dengue fever reported, there were 17 deaths. ${ }^{[6]}$ WHO (World Health Organization) bulletin updated as on March 2014, reported $40 \%$ of world population are at risk of exposure, nearly 5,000,000 people need hospitalization out of which $2.5 \%$ die. ${ }^{[20]}$

This study was focused on dengue fever, dengue hemorrhagic and dengue shock syndrome and their treatment outcome and effect of transfusion of blood products in dengue hemorrhagic fever and dengue shock syndromes.

All cases admitted to medical wards of NRI hospital from 1 September to 30 November, 2013 were taken for study that is, the extended monsoon period. All dengue seropositive cases admitted and treated in the hospital were included. The pregnant women and pediatric cases were excluded from the study.

\section{MATERIALS AND METHODS}

This is an observational study of seropositive dengue fever cases only. Fevers due to malaria, typhoid, other viral fevers and microbial infections were excluded from the study. The NRI Medical College 
Ethical Committee approval was obtained. All the admitted patients were assessed clinically for fever and dehydration and meticulously looked for any bleeding manifestations by visual, tourniquet testing, bleeding time as assessed by Duke method and were graded as per guidelines of National Vector Borne Control Programme. ${ }^{[1]}$ All patients were subjected to investigations that include complete blood counts, bleeding time, platelet counts, packed cell volume on daily basis and blood grouping. Liver function tests, renal functional tests, blood cultures, urine routine and stool examination for occult blood, electrocardiography, X-rays, ultrasound abdomen, computed tomography and magnetic resonance imaging scans and arterial blood gas analysis were done in needed cases. Serious and critically ill patients were treated in Intensive Care Unit and subjected to invasive procedures such as placement of central lines, lumbar puncture and upper GIT endoscopy. Serological evaluation of dengue fever cases were done by immunochromatographic technique using Ab Comb Standard Diagnostic Kit for NS 1 antigen and IgM and IgG antibody capture by Standard Diagnostic Kit. The test results conducted by above kits are in par with the results obtained by ELISA methods as reported by Prudhivi et al.,comparative serological evaluation study from our institute in $2014 . .^{[7]}$

The patients were managed as per Comprehensive guidelines WHO Regional Publication SEARO No. 29 New Delhi, 1999. ${ }^{[5]}$ However, patients with dengue hemorrhagic fever and dengue shock syndrome were treated with blood fresh frozen plasma (FFP) and random pooled donor (RDP) and single pooled donor if the platelet counts were below 50,000 cells/cu mm.

\section{OBSERVATIONS}

The total number of male and females fever cases admitted and treated from 1 September to 30 November, 2013 in medical wards of NRI General Hospital, Chinakakani are shown in Table 1 [Chart 1].

The total number of medical admissions for the 3 months period were 2104 of which 1204 were due to all fever cases other than dengue and 84 cases were due to seropositive dengue fever cases. Fever due to other causes contributed to $57.22 \%$, whereas fever due to dengue contributed about $3.99 \%$. The dengue fever cases admitted and treated are shown month-wise in Table 2 and in Chart 2.

The total number of dengue positive cases were 84 of which 54 were males and 30 were females in the ratio of $5: 3$.

The age groups affected predominantly were between 21 and 40 years contributed about $57.14 \%$, whereas group above 40 years to $30.9 \%$ and groups between the ages 15 and 20 years about $19.04 \%$ [Table 3 and Chart 3].

\section{CLINICAL PRESENTATION}

All the 84 cases had fever of varying duration from 2 days to 21 days at onset. Of 84 cases, 11 cases were $<3$ days, 38 cases were between

\begin{tabular}{|c|c|c|c|c|}
\hline Gender & $\begin{array}{c}\text { September } \\
2013\end{array}$ & $\begin{array}{c}\text { October } \\
2013\end{array}$ & $\begin{array}{l}\text { November } \\
2013\end{array}$ & Total \\
\hline Males & 459 & 425 & 368 & 1260 \\
\hline Females & 298 & 300 & 236 & 844 \\
\hline Total & 757 & 725 & 622 & 2104 \\
\hline
\end{tabular}

\begin{tabular}{|c|c|c|c|c|}
\hline Gender & $\begin{array}{c}\text { September } \\
2013 \\
\end{array}$ & $\begin{array}{c}\text { October } \\
2013 \\
\end{array}$ & $\begin{array}{c}\text { November } \\
2013\end{array}$ & Total \\
\hline Males & 22 & 19 & 13 & 54 \\
\hline Females & 09 & 15 & 06 & 30 \\
\hline Total & 31 & 34 & 19 & 84 \\
\hline
\end{tabular}

\begin{tabular}{lcc}
\multicolumn{3}{l}{ Table 3: Age-wise distribution of fever } \\
\hline Age group & Number of cases & Percentage \\
\hline $15-20$ & 16 & 19.04 \\
$21-30$ & 28 & 33.33 \\
$30-40$ & 20 & 23.80 \\
$41-50$ & 12 & 21.4 \\
50 and above & 08 & 9.5 \\
\hline
\end{tabular}

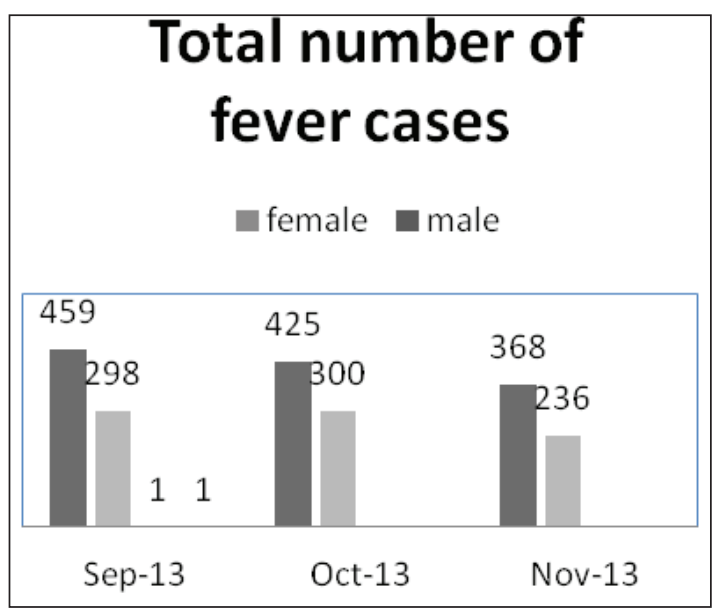

Chart 1: Total fever cases for 3 months

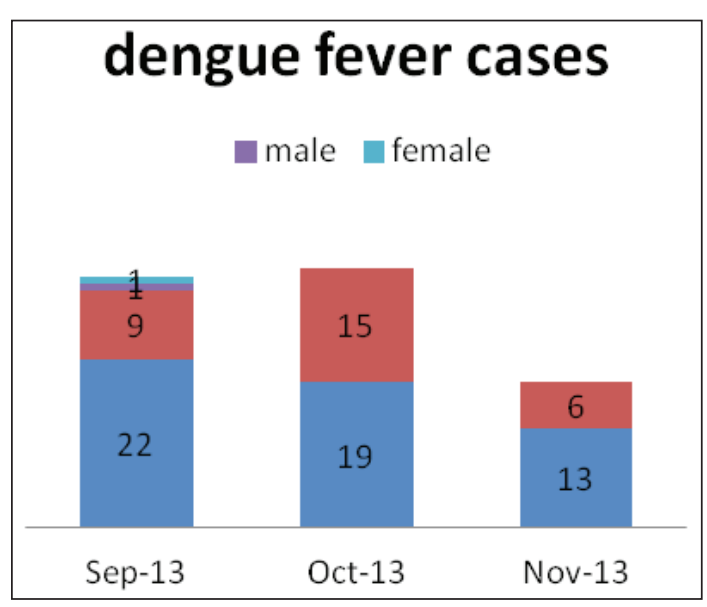

Chart 2: Male female dengue fever cases for 3 months 
3 and 5 days and 35 cases were between 5 and 21 days duration. Body pains, myalgia were present in $45 \%$ of cases, backache in $25 \%$, arthralgia in $25 \%$, headache $20 \%$, retro-orbital pain in $15 \%$, upper respiratory catarrh with dry cough $15 \%$ and breathlessness in $6 \%$. Notable symptoms were vomiting with pain abdomen in $25 \%$, diarrhea in 15\%, hyperemic rash all over the body in $10 \%$, petechial rashes $5 \%$, hepatomegaly $18 \%$, splenomegaly $15 \%$, altered sensorium with neck stiffness in 2 cases and seizures in one case. Ascites was found in $20 \%$ and bilateral pleural effusions in $6 \%$ cases as detected by ultrasound examination.

Bleeding Manifestations were seen in 25 cases, of which malena in 19 cases, epistaxis in 2 cases, gum bleeding in 2 cases and subconjunctival hemorrhage in 2 cases. Bleeding manifestations were graded as per WHO comprehensive guidelines, ${ }^{[5]}$ and it is shown in Table 4.

\section{INVESTIGATIONS}

Complete blood counts showed leukopenia in 31 cases, leukocytosis in 14 cases while the rest had normal counts. A low hemoglobin value of $<5 \mathrm{~g} \%$ was seen in 2 cases. $\mathrm{Hb} \%$ was in the range of $7-11 \mathrm{~g} \%$ in 15 cases and rest of the cases, it was above $11 \mathrm{~g} \%$. Bleeding time was raised above $3 \mathrm{~min}$ in 25 cases. Hematocrit was raised in 35\% cases, liver enzymes aspartate aminotransferase and alanine aminotransferase were raised up to $50-100 \mathrm{IU}$ in 28 cases and 100-200 IU in 30 cases and others had normal values.

Bilirubin and alkaline phosphatase levels were moderately raised in 5 cases, serum creatinine and BUN were moderately raised in 5 cases. Serum electrolytes were within normal limits.

Platelets counts were done on automated cell counter on daily basis. They were diminished below 100,000 cells/cu mm in 64 cases as shown in Table 5, but most notably $56.25 \%$ had thrombocytopenia in the range of $20,000-49,000$ cells/cu $\mathrm{mm}$, in $20.31 \%$ cases the counts were below 20,000 cells $/ \mathrm{mm}^{3}$ with bleeding manifestations Grade III to IV, demanding therapeutic intervention. All patients were discharged when the platelet counts reached above 1,50,000 cells $/ \mathrm{mm}^{3}$ and bleeding time was $<3 \mathrm{~min}$.

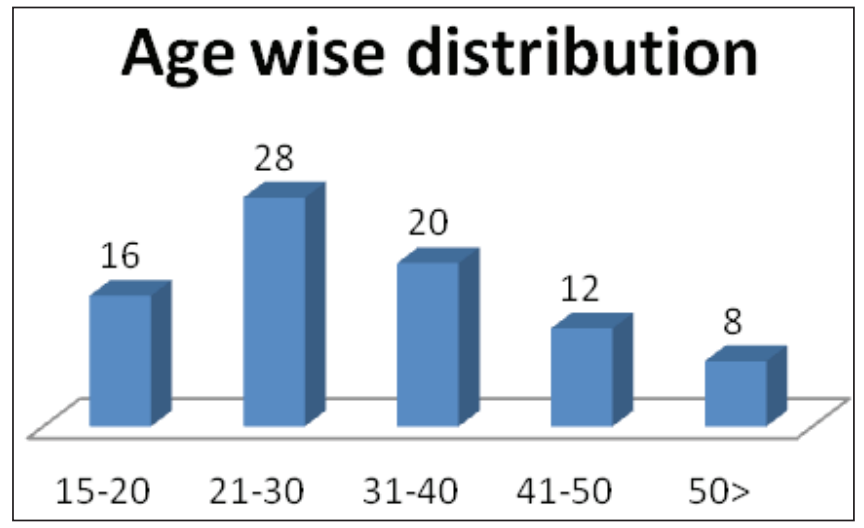

Chart 3: Age-wise distribution of dengue fever
Table 6 and pie diagram Chart 4 show various serological markers evaluated. NS1 was positive only in 9.5\% cases, NS1 and IgM were positive in $29.7 \%$ together representing the incidence of new cases. $\mathrm{IgG}$ positive $41.6 \%$ showing preponderance of old cases and about $15.5 \%$ cases of reinfection of old cases. The presence of $\operatorname{IgM}$ in 3 cases only without NS1 antigen could be due to early clearance of the antigen.

\section{MANAGEMENT}

Clinical evaluation of the cases was done as per National Vector Borne Diseases Control Programme Guidelines, WHO, 2009. ${ }^{[7]}$ The cases were categorized into dengue fever cases 55 , dengue hemorrhagic fever 27 cases and dengue shock syndrome 2 cases. In all cases, clinical and laboratory evaluation were done and

\begin{tabular}{llcc}
\multicolumn{3}{l}{ Table 4: WHO grading for bleeding in dengue fever } \\
\hline Grade & Manifestation & Number of cases & Percentage \\
\hline Grade I & Easy bruising & 25 & 29.76 \\
Grade II & Positive tourniquet test & 19 & 22.61 \\
Grade III & Spontaneous bleeding & 04 & 4.74 \\
Grade IV & No BP no pulse & 02 & 2.38 \\
\hline
\end{tabular}

$\mathrm{BP}=\mathrm{Blood}$ pressure

$\begin{aligned} & \text { Table 5: The reduced platelet counts in dengue } \\
& \text { fever cases }\end{aligned}$
\begin{tabular}{lcc}
\hline Platelet count in cells $/ \mathbf{m m}^{3}$ & Number of cases & Percentage \\
\hline $50,000-1,00,000$ & 15 & 23.43 \\
$20,000-49,000$ & 36 & 56.25 \\
$6000-20,000$ & 13 & 20.31 \\
\hline
\end{tabular}

\begin{tabular}{lcc}
\multicolumn{3}{l}{ Table 6: The dengue serological markers } \\
\hline Antigen/antibody detected & Number of cases (84) & Percentage \\
\hline NS1 & 08 & 9.5 \\
NS1 and IgM & 25 & 29.7 \\
IgM only & 03 & 3.5 \\
IgG & 35 & 41.6 \\
NS1, IgM, IgG & 13 & 15.4 \\
\hline
\end{tabular}

\section{Dengue fever Serology}

NS1 $\square$ NS1/lgM $\square \lg =\lg \square$ NS1 $\lg G \lg M$

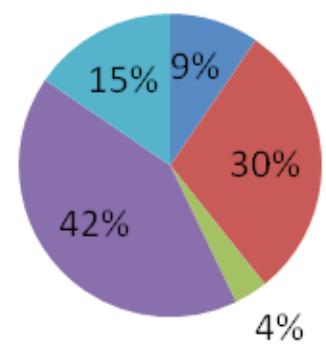

Chart 4: The percentage distribution serological markers 
dehydration was graded as mild, moderate and severe as per WHO Guidelines (2009). Intravenous fluids, either normal saline or Ringer lactate, were given at rate of $20 \mathrm{ml} / \mathrm{kg} / \mathrm{h}$ on the $1^{\text {st }}$ day and $10 \mathrm{ml} /$ $\mathrm{kg} / \mathrm{h}$ on subsequent days along with oral fluid supplementation until dehydration was corrected. Tablet paracetamol $650 \mathrm{mg}$ tid/qid was given to control fever. Two cases of the dengue shock syndrome were given fresh whole blood transfusions, FFP and single pooled donor platelets until recovery. The patients with increased risk of bleeding in dengue hemorrhagic and shock syndrome received blood products as shown in Table 7 . The platelet counts, bleeding time, were monitored on daily basis. All patients were monitored and discharged only when they were afebrile, bleeding time normalized, and platelet counts were above 1,50,000 per cu mm and above.

\section{DISCUSSION}

The number of dengue fever cases detected were highest in the month of September 2015 and October 2015 and tailed off in November 2013, which coincided with the increased vector activity during the preceding months. ${ }^{[2,3]}$ More number of cases reported with

Table 7: The transfusion of blood products in
dengue hemorrhagic and shock syndromes

RDP = Random donor platelets, $\mathrm{SDP}=$ Single donor platelets, FFP = Fresh frozen plasma abdominal complaints had hepatomegaly, splenomegaly and ascites and raised liver enzymes when compared with others. ${ }^{[9,10]}$ Two rare cases of aseptic meningitis with altered sensorium and neck stiffness were seen. Bleeding manifestations in the form of malena $(19 \%)$ was the most common compared to others..$^{[9,10]}$ Tables 8 and 9 show the manifestations of dengue fever as compared to other studies. ${ }^{[0,10,19]}$ With regard to duration of study and clinical manifestations and findings were comparable with the studies conducted by G.N. Malvege et al. from Colombo South Teaching Hospital, Sri Lanka, ${ }^{[10]}$ but differed from studies conducted by others. ${ }^{[2,13,19]}$ There were no cases of brain hemorrhage and strokes as reported by others. ${ }^{[3,8,11]}$

There was a clear indication for platelet transfusion in 13 cases of Grade III and IV bleeding who were given platelets transfusion with RDPs, single donor platelets (SDPs) and whole blood to keep platelet count above 50,000 and prevent further bleeding. ${ }^{[14,18]}$ Those patients with Grade II risk with platelet counts in the range of 21,000-49,000 were also given RDPs prophylactically. ${ }^{[16,17]}$ There were 4 patients with Grade I bleeding and platelet counts above 50,000 who were also given RDP on the insistence of the apprehensive patients and relatives. During the period of study, there were 2 cases of dengue shock syndrome who were managed in critical care setting and were given blood transfusions FFP and SDPs. There were no deaths in the above study.

Muhmmed Zaman Khan others have reported from Tertiary Care Hospital in Lahore Pakistan with 60 deaths due to various causes in 128,634 dengue fever cases. ${ }^{[18]}$ In a randomized control study by Muhummad Zaman Kaj and others at Jinah Medical College Lahore, 87 patients with dengue fever were studied. Half the patients whose platelet counts were below 30,000 cells/cu $\mathrm{mm}$ received platelet transfusions showed improvement with respect to platelet

\begin{tabular}{|c|c|c|c|c|}
\hline $\begin{array}{l}\text { Clinical features and } \\
\text { laboratory findings* }\end{array}$ & $\begin{array}{l}\text { NRI Hospital } \\
\text { South India }\end{array}$ & $\begin{array}{l}\text { Colombo South } \\
\text { Teaching Hospital }\end{array}$ & $\begin{array}{c}\text { Dhaka } \\
\text { Bangladesh }\end{array}$ & $\begin{array}{c}\text { WBUHS Kolkata } \\
\text { East India }\end{array}$ \\
\hline Myalgia (\%) & 45 & 76 & 85 & 41.5 \\
\hline Arthralgia (\%) & 25 & 57 & 68 & NS \\
\hline Flushed appearance (\%) & 10 & 64 & NS & NS \\
\hline Vomiting (\%) & 25 & 64 & 36 & NS \\
\hline Diarrhea (\%) & 15 & 29 & NS & NS \\
\hline Abdominal pain (\%) & 25 & 17 & 6 & NS \\
\hline Enlarged liver (\%) & 18 & 45 & 13 & NS \\
\hline Splenomegaly (\%) & 15 & 0.02 & NS & NS \\
\hline Bleeding manifestations (\%) & 30.5 & 42 & 16 & 13.51 \\
\hline Pleural effusion/ascites (\%) & $6 / 30$ & 11 & 5 & $18.9 / 8.1$ \\
\hline Shock & 2 & 14 & 1 & NS \\
\hline Thrombocytopenia (\%) & 63 & 79 & 23 & 37.84 \\
\hline Raised hematocrit (\%) & 5 & 22 & 17 & 40.9 \\
\hline Leucopenia (\%) & 31 & 31 & NS & NS \\
\hline Received fluids (\%) & 100 & 74 & NS & NS \\
\hline Platelet concentrates (\%) & 25 & 12 & NS & NS \\
\hline FFP (\%) & 2.2 & 5.5 & NS & NS \\
\hline Blood transfusions & 2.2 & NS & NS & NS \\
\hline Mortality (\%) & 0 & 3.7 & NS & NS \\
\hline
\end{tabular}

NS = Not stated, WBUHS = West bengal university of health sciences, FFP = Fresh frozen plasma 


\begin{tabular}{|c|c|c|c|c|}
\hline Study & Present & $\begin{array}{c}\text { G.N. } \\
\text { Malavige }^{[10]} \\
\end{array}$ & Pervin $^{[19]}$ & Mandal $^{[9]}$ \\
\hline Number studied & 84 & 108 & 97 & 74 \\
\hline Study period (months) & 03 & 04 & 06 & 10 \\
\hline DF/DHF & $55 / 27$ & $31 / 69$ & $79 / 18$ & $51 / 10$ \\
\hline $\begin{array}{l}\text { Primary dengue } \\
\text { infections }\end{array}$ & 39.2 & 34.3 & 47 & NS \\
\hline $\begin{array}{l}\text { Secondary dengue } \\
\text { infections }\end{array}$ & 15.4 & 65.7 & 53 & NS \\
\hline
\end{tabular}

counts. ${ }^{[18]}$ However, there was no significant difference in bleeding time between the treated and control group. They also reported 3 fatal cases of anaphylactic shock due to platelet transfusion and 2 deaths.

\section{CONCLUSIONS}

The dengue fever cases studied in our institute had more abdominal complaints with bleeding tendencies, mostly malena in 19\% as compared to others. The patients were treated as per the guidelines of National Vector Borne Control of Diseases protocol 2009, ${ }^{[5]}$ by correction of dehydration, recognition and treatment of bleeding complications in the early stages by appropriate transfusions of fluids and supportive therapy. Critically ill patients were given blood products as per University of North Carolina Chapel Hill guidelines. ${ }^{[16,17]}$

Whole blood transfusions were given to dengue shock syndrome who had Grade IV bleeding and were treated in critical care unit. There were no mortalities in our study. As word of caution routine platelet transfusion in dengue hemorrhagic fever can be associated with risk of complications including death, hence routine platelet transfusions should be avoided.

\section{REFERENCES}

1. Bandopathyay B, Bhattacharya I, Adhikary S, Konar J, Dawar N, Sarkar J, et al. ISRN Virology jrnl Volume 2013, Article ID.207580 [www.hindawi. com/journals/isrn/2013/207580].

2. Hati AK. Studies on dengue and dengue haemorrhagic fever (DHF) in West Bengal State, India. J Commun Dis 2006;38:124-9.

3. Sam SS, Omar SF, Teoh BT, Abd-Jamil J, AbuBakar S. Review of Dengue haemorrhagic fever fatal cases seen among adults: A retrospective study. PLoS Negl Trop Dis 2013;7:e2194.

4. WHO. Dengue Haemorrhagic fever and diagnosis, treatment, prevention and control. $2^{\text {nd }}$ ed. Geneva: WHO; 1997.

5. WHO. Prevention and control of dengue and dengue haemorrhagic fever, comprehensive guidelines. New Delhi: WHO Regional Publications SEARO No. 29; 2009.

6. Guidelines for clinical management of DF, DHF and DSS for indoor patients. Manual released by Directorate of National Vector Borne Diseases Control Programme, Director General of Health services, Ministry of Health and Family Welfare, government of India, 22, Shamnath Marg Delhi - 110054. Accessed vide http://nvbdcp.gov.in/doc/clinical guidelines PDF.

7. Prudhivi S, Yenigala BM, Myeneni RB. Incidence of dengue in rural hospital Chinakakani, Andhra Pradesh, South India and comparision of two commercaly available enzyme liked immunobsorbent assays with immunochromatographic rapid test. Int J Res Med Sci 2014;4:1534-40.

8. Ramos C, Sánchez G, Pando RH, Baquera J, Hernández D, Mota J, et al. Dengue virus in the brain of a fatal case of hemorrhagic dengue fever. J Neurovirol 1998;4:465-8.

9. Mandal SK, Ganguly J, Sil K, Chatterjee S, Chatterjee K, Sarkar P, Hazra S, Sardar D. Clinical profiles of dengue fever in teaching Hospital of Eastern India. Nat J Med Res 2013;3:173-6.

10. Malavige GN, Velathanthiri VG, Wijewickrama ES, Fernando $\mathrm{S}$, Jayaratne SD, Aaskov J, et al. Patterns of disease among adults hospitalized with dengue infections. QJM 2006;99:299-305.

11. Tripathi BK, Gupta B, Sinha RS, Prasad S, Sharma DK. Experience in adult population in dengue outbreak in Delhi. J Assoc Physicians India 1998;46:273-6.

12. Rahim MA, Sikder MS. Clinicopathologic manifestations and outcome of dengue fever and dengue haemorrhagic fever. Bangladesh Med Res Counc Bull 2005;31:36-45.

13. Chakravarti A, Kumaria R. Eco-epidemiological analysis of dengue infection during an outbreak of dengue fever, India. Virol J 2005;2:32.

14. Rahman M, Rahman K, Siddque AK, Shoma S, Kamal AH, Ali KS, et al. First outbreak of dengue hemorrhagic fever, Bangladesh. Emerg Infect Dis 2002;8:738-40.

15. Yulia Lin MD, British Columbia Provincial Blood Coordinating Proposed Guidelines for Platelet transfusion BCMJ: 2005;47:245-8.

16. Lin Y, Folk LM. Physician's guidelines for platelet transfusions. BCMJ 2005; $47: 245-8$.

17. University of North Carolina Hospital Chapel Hill N.C.Guidelines for Transfusion of Blood Products.Criteria for transfusion: Adults accessed vide http://labs.unchealthcare.org/forms/critical.pdf.

18. Assir MZ, Ahmad HI, Masood MA, Kamran U, Yusuf NW. Deaths due to dengue fever at a tertiary care hospital in Lahore, Pakistan. Scand J Infect Dis 2014;46:303-9.

19. Pervin M, Tabassum S, Mobark A, Mamun K, Islam M. Clinical and laboratory observation associated with 1000 Dengue outbreak in Dhaka Bangladesh. Dengue Bull 2004;28:96-106.

20. WHO Updates Media Centre Publications Fact Sheets No. 117; March, 2014

How to cite this article: Murali Mohan KK, Rao BB, Raghuram C, Gunnam S, Dharmateja D, Gopidi A. A clinical study of dengue fever cases: NRI Medical College, Chinakakani, Andhra Pradesh, South India. Int J Med Public Health 2015;5:367-71.

Source of Support: Nil, Conflicts of Interest: None declared. 